\title{
Competition among Large and Heterogeneous Small Firms*
}

\author{
Lijun $\operatorname{Pan}^{\dagger}$ \\ Nanjing University, Osaka University
}

\author{
Yongjin Wang $\ddagger$
}

Nankai University

May 25, 2020

\begin{abstract}
We extend the model of Parenti (2018) on large and small firms by introducing cost heterogeneity among small firms. We propose a novel necessary and sufficient condition for the existence of such a mixed market structure. Furthermore, in contrast to Parenti (2018), we show that in the presence of cost heterogeneity among small firms, trade liberalization may raise or reduce the mass of small firms in operation.
\end{abstract}

Keywords: large firms, small firms, firm heterogeneity, trade liberalization JEL classification: D4, L10, F11

\footnotetext{
* Pan gratefully acknowledges the financial support from the Grant-in-aid for Research Activity, Japan Society for the Promotion of Science (19K13681).

${ }^{\dagger}$ Main address: School of Economics, Nanjing University, Nanjing, China. Affiliated address: Institute of Social and Economic Research, Osaka University, Japan. Email: pan.lijun@hotmail.com

${ }^{\ddagger}$ School of Economics, Nankai University, Tianjin, China. Email: yjw@nankai.edu.cn.
} 


\section{Introduction}

Firm heterogeneity is prevalent in international trade. On the one hand, it is evident that firms are heterogeneous in terms of firm size, with a few dominant large exporters and a host of negligible small firms 1 On the other hand, small firms also display heterogeneity in the form of productivity differences 2 This note attempts to address these two types of firm heterogeneity in a coherent model and examine the impact of trade liberalization.

We draw on the model in Parenti (2018) where large and small firms coexist, but goes beyond that model by introducing cost heterogeneity among small firms. In our model, large firms are treated as established incumbent oligopolists, whereas small firms are treated as monopolistic competitors who endogenously make entry decisions and face initial uncertainty about their future productivity prior to entry. The heterogeneity among small firms is in the spirit of Melitz-Ottaviano type's heterogeneity 3

First, we propose a novel necessary and sufficient condition for the existence of such a mixed market structure in a closed economy, accommodating the cost heterogeneity among small firms. Large and small firms coexist if (i) the marginal cost of large firms is strictly lower than that of the least efficient small firm in operation, and (ii) consumers' preferences on the differentiated goods are sufficiently high, the number of large firms is not too high, and the cost of large firms is not too low. The former condition guarantees that large firms earn positive profits, and the latter condition guarantees a positive mass of small firms in operation.

Second, in contrast to Parenti (2018), we show that bilateral trade liberalization may raise the mass of small firms selling in each country. Assuming that small firms share the same cost and do not export, Parenti (2018) finds that trade liberalization leads to the expansion of large firms and decreases the mass of small firms selling in each country. However, we introduce cost heterogeneity among small firms and allow the most efficient ones to export. Therefore, a reduction in trade cost as a result of bilateral trade liberalization not only reduces the export cost of large firms, but also lowers the trade cost of small firms. The former effect, which is consistent with Parenti (2018), generates a negative impact on the mass of small firms, whereas the latter effect generates a positive impact on the mass of small firms. The impact of trade liberalization on the mass of small firms selling in each country depends on these two opposing effects. When the number and cost of large firms are sufficiently high, the former effect dominates, and trade liberalization decreases the mass of small firms. Otherwise, the latter effect dominates, and trade liberalization increases the mass of small firms. We also find that trade liberalization may raise the mass of small producers in each country.

This paper contributes to the recent studies on the mixed market structure with large and small firms. Assuming that small firms have identical cost, Shimomura and Thisse (2012) and Pan and Hanazono (2018) identify the condition for the coexistence of large and small firms and examine the impact of a large firm's entry in a closed economy. Complementary to these works, this paper derives a new coexistence condition incorporating cost heterogeneity among small firms and investigates the impact of trade

\footnotetext{
${ }^{1}$ See Parenti (2018).

${ }^{2}$ See Melitz (2003) and Melitz and Ottaviano (2008).

${ }^{3}$ Representative works include Melitz (2003) and Melitz and Ottaviano (2008).
} 
liberalization. Although our results can be regarded as an extension of Parenti (2018), they open a new channel through which the most efficient small firms could export and benefit from trade liberalization.

Our results also relate to the research on trade liberalization. In the model with monopolistic competition and firm heterogeneity, Melitz (2003) and Melitz and Ottaviano (2008) show that bilateral trade liberalization raises the mass of small firms selling in each country. On the contrary, in our model, bilateral trade liberalization may reduce the mass of small firms due to the expansion in the export of large firms. In the Stackelberg model where large firms are leaders and can export whereas small firms are followers and sell only in the domestic market, Pan and Tabuchi (2019) also find that free trade reduces the number of small firms. In contrast, allowing for the export by efficient small firms, we find that trade liberalization may raise the mass of small firms because the exporting small firms also benefit from trade liberalization.

\section{Closed Economy}

Consider an economy with $L$ consumers, each supplying one unit of labor inelastically. Each consumer consumes two types of goods, a homogeneous good and differentiated goods. The homogeneous good is produced under constant returns to scale at unit cost and perfect competition, which implies a unit wage. The differentiated goods are supplied by a discrete number $N$ of large firms $n=1, \ldots, N$, and a continuum of small firms indexed by $i \in[0, M]$. Occupying a substantial market share, each large firm behaves strategically as an oligopolist. Being negligible in the market, each small firm behaves non-strategically as a monopolistic competitor.

\section{$2.1 \quad$ Preferences}

All consumers share the same utility function given by

$$
U=\alpha\left(\int_{0}^{M} x_{i} d i+\sum_{n=1}^{N} X_{n}\right)-\frac{\beta}{2}\left[\int_{0}^{M}\left(x_{i}\right)^{2} d i+\sum_{n=1}^{N}\left(X_{n}\right)^{2}\right]-\frac{\gamma}{2}\left(\int_{0}^{M} x_{i} d i+\sum_{n=1}^{N} X_{n}\right)^{2}+x_{0},
$$

where $x_{i}$ represents the individual consumption of the good produced by small firm $i$, and $X_{n}$ represents the individual consumption of the good produced by large firm $n$. The numeraire good is represented by $x_{0}$. The demand parameters $\alpha>0$ and $\gamma>0$ capture the degree of substitutability between the varieties of the differentiated product and the numeraire, and $\beta>0$ represents the degree of differentiation between the differentiated varieties.

Assuming that consumers have positive demands for the numeraire good, the inverse demand for small firm $i$ and large firm $n$ are respectively

$$
\begin{gathered}
p_{i}=\alpha-\beta x_{i}-\gamma \mathbf{X}, \forall i \in[0, M] \\
P_{n}=\alpha-\beta X_{n}-\gamma \mathbf{X}, n=1, \ldots, N
\end{gathered}
$$


whenever $x_{i}>0, X_{n}>0$, and $\mathbf{X}=\int_{0}^{M} x_{i} d i+\sum_{n=1}^{N} X_{n}$ is the individual total consumption of the differentiated good.

Inverse demands (21) and (3) can be inverted to the demands for small firm $i$ and large firm $n$ :

$$
\begin{gathered}
q_{i}=L x_{i}=\frac{\alpha L}{\beta+\gamma(M+N)}-\frac{L}{\beta} p_{i}+\frac{L}{\beta} \frac{\gamma}{\beta+\gamma(M+N)} \mathbf{P}, \forall i \in[0, M] \\
Q_{n}=L X_{n}=\frac{\alpha L}{\beta+\gamma(M+N)}-\frac{L}{\beta} P_{n}+\frac{L}{\beta} \frac{\gamma}{\beta+\gamma(M+N)} \mathbf{P}, n=1, \ldots, N
\end{gathered}
$$

where $\mathbf{P}=\int_{0}^{M} p_{i} d i+\sum_{n=1}^{N} P_{n}$ is the aggregate price. To ensure a positive consumption, i.e., $q_{i} \geq 0$ and $Q_{n} \geq 0$, the prices of large and small firms should satisfy

$$
p_{i}, P_{n} \leq \frac{1}{\beta+\gamma(M+N)}(\alpha \beta+\gamma \mathbf{P})=p_{\max },
$$

where $p_{\max }$ represents the price at which demand for the good is driven to zero.

\section{$2.2 \quad$ Firms}

We consider a 2-stage game. In the first stage, small firms enter the market. In the second stage, large and small firms who have entered the market compete in price.

Small Firms Entry in the differentiated product sector is costly as each firm incurs product development and production start-up costs. Subsequent production exhibits constant returns to scale at a marginal cost $c$. Following Melitz and Ottaviano (2008), Research and development yield uncertain outcomes for $c$, and firms learn about this cost level only after making the irreversible investment $f_{E}$ required for entry. We assume that the marginal cost of each small firm is a draw from a common and known distribution $G(c)$ with support $\left[0, c_{M}\right]$. Since the entry cost is sunk, firms that can cover their marginal cost survive and produce. All other firms exit the industry.

Substituting the demand function (44), the gross profit of small firm $i$ with marginal cost $c_{i}$ can be expressed as

$$
\pi_{i}=\left(p_{i}-c_{i}\right)\left(\frac{\alpha L}{\beta+\gamma(M+N)}-\frac{L}{\beta} p_{i}+\frac{L}{\beta} \frac{\gamma}{\beta+\gamma(M+N)} \mathbf{P}\right), \forall i \in[0, M] .
$$

Large Firms Large firms are established incumbents and produce at marginal cost $C$. Substituting the demand function (5), the profit of large firm $n$ can be expressed as

$$
\Pi_{n}=\left(P_{n}-C\right)\left(\frac{\alpha L}{\beta+\gamma(M+N)}-\frac{L}{\beta} P_{n}+\frac{L}{\beta} \frac{\gamma}{\beta+\gamma(M+N)} \mathbf{P}\right), n=1, \ldots, N .
$$




\subsection{The Equilibrium Analysis}

\subsubsection{Stage 2}

Small Firms Small firm $i$ maximizes its profit with respect to its price $p_{i}$, treating the aggregate price $\mathbf{P}$ as given since its market share is negligible. The profit maximizing price $p_{i}$ and quantity $q_{i}$ then satisfy

$$
q_{i}\left(c_{i}\right)=\frac{L}{\beta}\left[p_{i}\left(c_{i}\right)-c_{i}\right],
$$

If the profit maximizing price $p_{i}$ is above the price bound $p_{\max }$ from (6), then small firm $i$ exits. Let $c_{D}$ denote the cost of the small firm who is indifferent about remaining in the industry. This firm earns zero profit as its cost is equal to its marginal cost, that is, $p\left(c_{D}\right)=c_{D}=p_{\max }$, and its demand level $q\left(c_{D}\right)$ is driven to 0 . We assume that $c_{M}$ is high enough to be above $c_{D}$, so that some firms with cost draws between these two levels exit. All firms with cost below $c_{D}$ earn positive profits (gross of the entry cost) and remain in the industry. Substituting (6), and knowing that $p_{\max }=c_{D}$, the first order condition of a small firm with $c<c_{D}$ yields its optimal price $p(c)$ and quantity $q(c)$ :

$$
\begin{gathered}
p(c)=\frac{1}{2}\left(c_{D}+c\right), \\
q(c)=\frac{L}{2 \beta}\left(c_{D}-c\right),
\end{gathered}
$$

and the profit can be expressed by

$$
\pi(c)=\frac{L}{4 \beta}\left(c_{D}-c\right)^{2} .
$$

Large Firms Different from a small firm, who treats the aggregate price $\mathbf{P}$ parametrically, a large firm behaves strategically and internalizes its impact on $\mathbf{P}$. Large firm $n$ maximizes its profit given by (8), yielding the optimal price

$$
P_{n}=P=\frac{c_{D}+(1-\Theta) C}{2-\Theta}, n=1, \ldots, N
$$

where $\Theta=\gamma /[\beta+\gamma(M+N)] \in(0,1)$ represents the internalization by the large firm. Due to the internalization, a large firm's price depends on the threshold cost $c_{D}$ of small firms and the mass $M$ of small firms, which are endogenously determined by the free entry condition in the first stage. Moreover, incurring the same marginal cost $C$, large firms set the same price $P$.

Similar to a small firm, a large firm stops operation if and only if the profit maximizing price $P$ is above the price bound $p_{\max }$. Since $p_{\max }=c_{D}$, the necessary and sufficient condition for the existence of large firms is $C<c_{D}$ 出

\footnotetext{
${ }^{4}$ We assume that large firms incur zero fixed cost. If the fixed cost is positive, then the condition for the existence of large firms should be stricter.
} 


\subsubsection{Stage 1}

Prior to entry, the expected profit of a small firm is $\int_{0}^{c_{D}} \pi(c) d G(c)-f_{E}$. Substituting (12), the free entry condition can be rewritten as

$$
\frac{L}{4 \beta} \int_{0}^{c_{D}}\left(c_{D}-c\right)^{2} d G(c)=f_{E}
$$

which determines the cost cut-off $c_{D}$.

To obtain tractable results, we assume the Pareto parametrization for the cost draws of small firms, i.e.,

$$
G(c)=\left(\frac{c}{c_{M}}\right)^{k}, c \in\left[0, c_{M}\right] .
$$

Given this parametrization, the cut-off cost level $c_{D}$ determined by (14) is then

$$
c_{D}^{*}=\left(\frac{\beta \phi}{L}\right)^{\frac{1}{k+2}},
$$

where $\phi=2(k+1)(k+2)\left(c_{M}\right)^{k} f_{E}$ is the technology index.

Substituting the optimal prices of small and large firms given by (10) and (13), and using that $p_{\max }=c_{D}$, (6) can be expressed as

$$
\frac{\left(\alpha-c_{D}^{*}\right) \beta}{\gamma}=\frac{M c_{D}^{*}}{2(k+1)}+N\left(c_{D}^{*}-C\right) \frac{1-\Theta(M)}{2-\Theta(M)},
$$

In equation (17), the LHS is constant and positive, whereas the RHS increases with $M$. Let $M^{*}$ be the equilibrium mass of small firms. To ensure that $M^{*}>0$, the RHS should be smaller than the LHS when $M=0$. Therefore, equation (17) uniquely determines a positive mass $M^{*}$ of small firms in operation if and only if

$$
\frac{\left(\alpha-c_{D}^{*}\right) \beta}{\gamma}>N\left(c_{D}^{*}-C\right) \frac{\beta+\gamma(N-1)}{2 \beta+\gamma(2 N-1)} .
$$

As shown earlier, large firms earn a positive profit if and only if $C<c_{D}$. Substituting the equilibrium cost cut-off of small firms in (16), we establish the condition for the coexistence of large and small firms in Proposition 1.

Proposition 1 There exists a unique mixed market equilibrium where large and small firms coexist if and only if (i) $C<(\beta \phi / L)^{\frac{1}{k+2}}$ and (ii) $\left[\alpha-(\beta \phi / L)^{\frac{1}{k+2}}\right] \beta>\gamma N\left[(\beta \phi / L)^{\frac{1}{k+2}}-\right.$ $C][\beta+\gamma(N-1)] /[2 \beta+\gamma(2 N-1)]$.

The first condition, which guarantees that large firms earn positive profits, requires that the cost of large firms be smaller than the cost cutoff of small firms, which is satisfied if the technology index $\phi$ is sufficiently high and the market size $L$ is not too large. The second condition, which guarantees a positive mass of small firms, is satisfied if the consumer's preference for the differentiated good $\alpha$ is sufficiently high, the cost $C$ of large firms is not too low in comparison with the cost cutoff $(\beta \phi / L)^{\frac{1}{k+2}}$ of small firms, and the number $N$ of large firms is not too large. 
In models with the coexistence of large and small firms, see, e.g., Shimomura and Thisse (2012), Parenti (2018), and Pan and Hanazono (2018), it is commonly assumed that small firms share the same technology. When large firms are single-product and facing zero fixed cost, their assumption implies large firms operate if and only if $C<$ $c+2 \sqrt{\beta f_{E}}$. However, when we allow the small firms to be heterogeneous and facing cost uncertainty prior to entry, Proposition 1 indicates that large firms should be more efficient than the least productive small firm to survive.

\section{Open Economy}

In the previous section, we considered a closed-economy model. In this section, we extend the model to an open economy, and examine the impact of trade liberalization. Following Parenti (2018), we consider two symmetric countries, $H$ and $F$, each with the same market size and distribution of firms. Specifically, each country has $L$ consumers who share the same preferences, leading to the inverse demand functions (2) and (3). In addition, in each country, there are $N$ large firms with marginal cost $C$, and small firms share the same cost distribution given by (15). The two markets are segmented, although firms can produce in one market and sell in the other at a trade cost $\tau$. We assume that large and small firms exist and export in both countries, and we will identify the condition in the analysis.

The aggregate price in country $h$ is then defined by

$$
\mathbf{P}^{h}=\int_{0}^{M^{h}} p_{i} d i+N P_{D}^{h}+N P_{X}^{f}, h, f=H, F, h \neq f
$$

where $M^{h}$ is the mass of small firms selling in country $h$, including both domestic small firms and foreign small exporters, $P_{D}^{h}$ represents the price of domestic large firms, and $P_{X}^{f}$ represents the delivered price of foreign large firms.

The price threshold for positive demand in country $h$ is then given by

$$
p_{\max }^{h}=\frac{1}{\beta+\gamma\left(M^{h}+2 N\right)}\left(\alpha \beta+\gamma \mathbf{P}^{h}\right) .
$$

\subsection{The Equilibrium Analysis}

\subsubsection{Stage 2}

Small Firms Let $p_{D}^{h}(c)$ and $q_{D}^{h}(c)$ represent the domestic levels of profit maximizing price and quantity sold for a small firm producing in country $h$ with cost $c$. Such a small firm may also export output $q_{X}^{h}(c)$ at a delivered price $p_{X}^{h}(c)$. The delivered cost of a unit with cost $c$ to the foreign country is $\tau c$, where $\tau>1$ and is the same across all exporting firms. Since the markets are segmented, small firms independently maximize the profits in the domestic and foreign markets. Let $\pi_{D}^{h}(c)=\left[p_{D}^{h}(c)-c\right] q_{D}^{h}(c)$ and $\pi_{X}^{h}(c)=\left[p_{X}^{h}(c)-\tau c\right] q_{X}^{h}(c)$ denote the maximized value of these profits as a function of the firm's marginal cost $c$. 
Analogously to (9), the profit maximizing prices and quantities must satisfy: $q_{D}^{h}(c)=$ $(L / \beta)\left[p_{D}^{h}(c)-c\right]$ and $q_{X}^{h}(c)=(L / \beta)\left[p_{X}^{h}(c)-\tau c\right]$. As was the case in the closed economy, only the small firms that earn non-negative profits in a market (domestic or export) will choose to sell in that market. This leads to similar cost cut-off rules for small firms selling in either market. Let $c_{D}^{h}$ denote the upper bound cost for small firms selling in their domestic market, and let $c_{X}^{h}$ denote the upper bound cost for small exporters from $h$ to $f$. These cutoffs must then satisfy:

$$
\begin{aligned}
& c_{D}^{h}=\sup \left\{c: \pi_{D}^{h}(c)>0\right\}=p_{\max }^{h}, \\
& c_{X}^{h}=\sup \left\{c: \pi_{X}^{h}(c)>0\right\}=\frac{p_{\max }^{f}}{\tau} .
\end{aligned}
$$

This implies $c_{X}^{f}=c_{D}^{h} / \tau$ : trade barriers make it harder for small firms to break even in the foreign market than in the domestic market.

As was the case in the closed economy, the optimal prices and quantities are also functions of the cost cutoffs:

$$
\begin{aligned}
& p_{D}^{h}(c)=\frac{1}{2}\left(c_{D}^{h}+c\right), q_{D}^{h}(c)=\frac{L}{2 \beta}\left(c_{D}^{h}-c\right), \\
& p_{X}^{h}(c)=\frac{\tau}{2}\left(c_{X}^{h}+c\right), q_{X}^{h}(c)=\frac{L}{2 \beta} \tau\left(c_{X}^{h}-c\right),
\end{aligned}
$$

which yield the maximized profit levels:

$$
\begin{aligned}
\pi_{D}^{h}(c) & =\frac{L}{4 \beta}\left(c_{D}^{h}-c\right)^{2}, \\
\pi_{X}^{h}(c) & =\frac{L}{4 \beta} \tau^{2}\left(c_{X}^{h}-c\right)^{2} .
\end{aligned}
$$

Large Firms Similar to the closed economy, we assume that all the large firms share the same marginal cost $C$ in production, and the delivered cost of a unit to the foreign country is $\tau C$. Let $P_{D}^{h}$ and $Q_{D}^{h}$ represent the domestic levels of profit maximizing price and quantity sold for a large firm producing in country $h$. The large firm also exports output $Q_{X}^{h}$ at a delivered price $P_{X}^{h}$. Analogously to (13), the profit maximizing domestic and export prices are

$$
\begin{aligned}
P_{D}^{h} & =\frac{c_{D}^{h}+\left(1-\Theta^{h}\right) C}{2-\Theta^{h}}, \\
P_{X}^{h} & =\tau \frac{c_{X}^{h}+\left(1-\Theta^{f}\right) C}{2-\Theta^{f}},
\end{aligned}
$$

where $\Theta^{h}=\gamma /\left[\beta+\gamma\left(M^{h}+2 N\right)\right]$ and $\Theta^{f}=\gamma /\left[\beta+\gamma\left(M^{f}+2 N\right)\right]$. A large firm in country $h$ stops selling in the domestic market if and only if $P_{D}^{h}$ is above the price bound $p_{\max }^{h}$. Since $p_{\max }^{h}=c_{D}^{h}$, the necessary and sufficient condition for the domestic operation of large firms is $C<c_{D}^{h}$. Furthermore, it stops exporting if and only if $P_{X}^{h}$ is above the price bound $p_{\max }^{f}$ (where $f \neq h$ ). Since $p_{\max }^{f}=\tau c_{X}^{h}$, the necessary and sufficient condition for the existence of exporting large firms is $C<c_{X}^{h}$. These two conditions indicate that 
large firms share the same cost cutoffs with small firms in both domestic and foreign markets.

Therefore, large firms in both countries export if and only if $C<\min \left\{c_{X}^{H}, c_{X}^{F}\right\}$.

\subsubsection{Stage 1}

Entry of small firms is unrestricted in both countries. Small firms choose a production location prior to entry and pay the sunk entry cost. We assume that both countries share the same technology for small firms - referenced by the entry cost $f_{E}$ and cost distribution $G(c)$. Therefore, the free entry condition is expressed as

$$
\frac{L}{4 \beta} \int_{0}^{c_{D}^{h}} \pi_{D}^{h}(c) d G(c)+\int_{0}^{c_{X}^{h}} \pi_{X}^{h}(c) d G(c)=f_{E}
$$

With Pareto parametrization for the cost draws $G(c)$ in both countries, the free entry condition can be rewritten as

$$
\left(c_{D}^{h}\right)^{k+2}+\tau^{2}\left(c_{X}^{h}\right)^{k+2}=\frac{\beta \phi}{L} .
$$

Since $c_{X}^{f}=c_{D}^{h} / \tau$, the free entry condition (23) can be expressed as

$$
\left(c_{D}^{h}\right)^{k+2}+\rho\left(c_{D}^{f}\right)^{k+2}=\frac{\beta \phi}{L},
$$

where $\rho=(\tau)^{-k} \in(0,1)$ is an inverse measure of trade costs (the "freeness" of trade). This system can be solved for the cutoffs in both countries:

$$
c_{D}^{h *}=c_{D}^{f *}=c_{D}^{*}=\left[\frac{\beta \phi}{L(1+\rho)}\right]^{1 /(k+2)},
$$

by which the average cost of small firms selling in each country is $\bar{c}_{D}^{*}=k c_{D}^{*} /(k+1)$.

By (18) and (22), the aggregate price in country $h$ is given by

$$
\mathbf{P}^{h}=\frac{M^{h}(2 k+1)}{2(k+1)} c_{D}^{*}+N \frac{c_{D}^{*}+\left(1-\Theta^{h}\right) C}{2-\Theta^{h}}+N \frac{c_{D}^{*}+\left(1-\Theta^{f}\right) \tau C}{2-\Theta^{f}},
$$

Substituting $\mathbf{P}^{h}$, (18) can be expressed as

$$
\frac{\left(\alpha-c_{D}^{*}\right) \beta}{\gamma}=\frac{M^{h}}{2} \frac{c_{D}^{*}}{k+1}+N\left(c_{D}^{*}-C\right) \frac{1-\Theta^{h}}{2-\Theta^{h}}+N\left(c_{D}^{*}-\tau C\right) \frac{1-\Theta^{h}}{2-\Theta^{h}} .
$$

which uniquely determines the mass of small firms in country $h$ because the RHS strictly increases with $M^{h}$. (25) also implies that $M^{f}=M^{h}=M$ and hence $\Theta^{f}=\Theta^{h}=\Theta$. Therefore, (25) could be reduced to

$$
\frac{\left(\alpha-c_{D}^{*}\right) \beta}{\gamma}=\frac{M}{2} \frac{c_{D}^{*}}{k+1}+\frac{1-\Theta(M)}{2-\Theta(M)} N\left[\left(c_{D}^{*}-C\right)+\left(c_{D}^{*}-\tau C\right)\right],
$$

which uniquely determines the equilibrium mass $M^{*}$ of small firms selling in each country. To ensure that $M^{*}>0$, we assume that $\left(\alpha-c_{D}^{*}\right) \beta / \gamma>N\left[\left(c_{D}^{*}-C\right)+\left(c_{D}^{*}-\tau C\right)\right][\beta+$ $\gamma(N-1)] /[2 \beta+\gamma(2 N-1)]$. 


\subsection{Trade Liberalization}

Based on the above equilibrium analysis, now we examine how bilateral trade liberalization impacts the mass of small firms.

First, (24) indicates that a reduction in trade cost as a result of bilateral trade liberalization decreases the cost cut-off of small firms, that is, $d c_{D}^{*} / d \tau>0$.

Now we examine the impact of trade liberalization on the mass of small firms selling in each country, including both domestic small producers and foreign small exporters. By (26), we have

$$
\frac{d M}{d \tau}=-\frac{\left[\frac{\alpha \beta}{\gamma}+(1+\tau) N C\right] \frac{k}{k+2} \frac{\rho}{\rho+1} \frac{1}{\tau}-\frac{1-\Theta}{2-\Theta} N C}{\frac{c_{D}^{*}}{2(k+1)}+\left(\frac{\Theta}{2-\Theta}\right)^{2}\left[\left(c_{D}^{*}-C\right)+\left(c_{D}^{*}-\tau C\right)\right] N},
$$

which is negative if and only if

$$
\frac{2-\Theta\left(M^{*}\right)}{1-\Theta\left(M^{*}\right)} \frac{\alpha \beta}{\gamma}>\left(\frac{2 \rho+k+2}{k \rho} \tau-1\right) N C,
$$

where $M^{*}$ is the equilibrium mass of small firms determined by (26).

Proposition 2 establishes the impact of bilateral trade liberalization on the mass of small firms selling in each country.

Proposition $2 A$ decrease in trade costs as a result of bilateral trade liberalization increases the mass of small firms selling in each country if $(\alpha \beta / \gamma)\left[2-\Theta\left(M^{*}\right)\right] /[1-$ $\left.\Theta\left(M^{*}\right)\right]>[(2 \rho+k+2) \tau /(k \rho)-1] N C$, and decreases the mass of small firms selling in each country otherwise.

A reduction in trade cost generates two opposing effects on the mass of small firms selling in each country. First, trade liberalization reduces the export cost and hence enables more small firms to export, which potentially increases the mass of small firms. Second, a decrease in trade cost also generates cost savings on the exported goods of large firms, which induces large firms to expand export. This generates competitive pressure on small firms and may reduce the mass of surviving small firms. As marginal cost $C$ rises, the cost savings become stronger and lead to more aggressive exporting behavior by large firms. Furthermore, the aggregation of such aggressive exports increases with the number $N$ of large firms. Therefore, condition (27) holds as long as the number $N$ or marginal cost $C$ of large firms is not too high.

Last, we show that bilateral trade liberalization may also raise the mass of small producers in each country. By symmetry, in each country, there are $M_{E} G\left(c_{D}\right)$ domestic small producers and $M_{E} G\left(c_{X}\right)$ foreign small exporters. Thus, $M_{E} G\left(c_{D}\right)+M_{E} G\left(c_{D} / \tau\right)=$ $M$, by which the mass of small entrants in each country can be expressed as $M_{E}=$ $M\left(c_{M} / c_{D}\right)^{k} /(1+\rho)$. The mass of small producers in each country is then expressed by

$$
M_{D}=M_{E} G\left(c_{D}\right)=\frac{M}{1+\rho} .
$$


The impact of a reduction in trade cost on the mass of small producers is then given by

$$
\frac{d M_{D}}{d \tau}=\frac{1}{1+\rho}\left[\frac{d M}{d \tau}+\frac{k \rho M}{(1+\rho) \tau}\right] .
$$

A reduction in trade cost impacts the mass $M_{D}$ of domestic small producers through (a) the change in the mass $M$ of small firms selling in each country and (b) the reallocation between domestic producers and foreign exporters within the group of small firms. The change in the mass of small firms selling in each country, according to Proposition 2 , is positive as long as thenumber and marginal cost of large firms are not too high. Furthermore, trade liberalization invites the most productive small firms to increase export, which makes competition tougher and may force some of the least productive small producers to exit. This generates a negative impact on the mass of domestic small producers. Therefore, if the rise in the total mass of small firms selling in each country outweighs the negative impact from the export expansion by the most productive small firms, then trade liberalization would also raise the mass of small producers in each country. Otherwise, trade liberalization reduces the mass of small producers. Proposition 3 establishes this result with the precise condition.

Proposition 3 A decrease in trade costs as a result of bilateral trade liberalization increases the mass of small producers if

$\frac{\alpha \beta / \gamma+(1+\tau) N C}{k+2}>\frac{M^{*} c_{D}^{*}}{2(k+1)}+M^{*} N\left[2 c_{D}^{*}-(1+\tau) C\right]\left[\frac{\Theta\left(M^{*}\right)}{2-\Theta\left(M^{*}\right)}\right]^{2}+N C \frac{(1+\rho) \tau}{\rho k} \frac{1-\Theta\left(M^{*}\right)}{2-\Theta\left(M^{*}\right)}$,

and decreases the mass of small producers otherwise.

Here $c_{D}^{*}$ and $M^{*}$ are the equilibrium values determined in (24) and (26). Owing to the expansion of small exporters as a result of trade liberalization, the range of parameters where trade liberalization increases the mass of small producers narrows down 5

We conclude by highlighting the distinction between our results and those in Parenti (2018). Take Proposition 2 for instance. Assuming that small firms share the same cost and do not export, Parenti (2018) finds that trade liberalization decreases the mass of small firms. In Proposition 2, we go a step further by introducing cost heterogeneity among small firms and allowing a portion of small firms to export, identifying two opposing effects of trade liberalization on the mass of small firms. The second effect, which reduces the mass of small firms, is consistent with Parenti (2018), whereas the first effect is novel here. The insights of Proposition 2 extend to Proposition 3.

\section{References}

[1] Melitz, M. J., 2003. The impact of trade on intra-industry reallocations and aggregate industry productivity. Econometrica, 71(6), 1695-1725.

\footnotetext{
${ }^{5}$ We identify both the case when $d M_{D}^{*} / d \tau>0$ and that when $d M_{D}^{*} / d \tau<0$ by numerical analysis. For instance, when $\alpha=0.6, \beta=\gamma=1, N=1, C=0.01, L=100, f_{E}=1$, and $\tau=1.5, d M_{D}^{*} / d \tau<0$; when $\alpha=2.4, \beta=\gamma=1, N=2, C=0.02, L=100, f_{E}=1$, and $\tau=1.5, d M_{D}^{*} / d \tau>0$.
} 
[2] Melitz, M. J., and Ottaviano, G. I., 2008. Market size, trade, and productivity. The Review of Economic Studies, 75(1), 295-316.

[3] Pan, L., and Hanazono, M., 2018. Is a big entrant a threat to incumbents? The role of demand substitutability in competition among the big and the small, Journal of Industrial Economics, 66(1), 30-65.

[4] Pan, L., and Tabuchi, T., 2019. Free trade agreement with endogenous market structure. The Japanese Economic Review, 70(4), 426-445.

[5] Parenti, M., 2018. Large and small firms in a global market: David vs. Goliath. Journal of International Economics, 110, 103-118.

[6] Shimomura, K. I., and Thisse, J. F., 2012. Competition among the big and the small, The RAND Journal of Economics. 43(2), 329-347. 